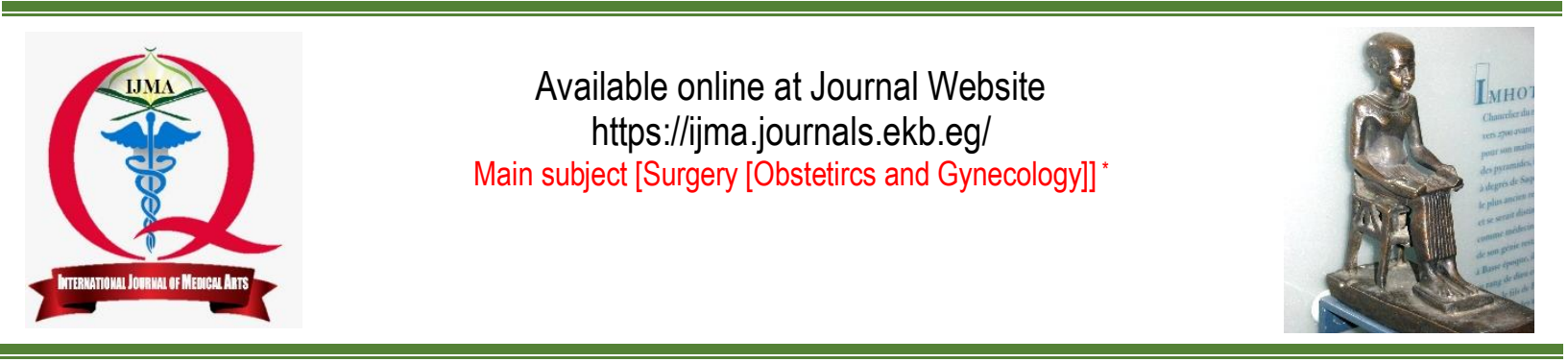

Original article

\title{
Laparoscopic versus Abdominal Hysterectomy for Obese Women with Benign Diseases
}

\author{
Mohamed Elsayed Thapet ${ }^{a}$; Mahmoud Farouk Midan a; Mahmoud Salah Mahmoud Rady a; Hossam \\ Abdelmageed Abdou ${ }^{\mathbf{b}}$
}

Department of Obstetrics and Gynecology, Damietta Faculty of Medicine, Al-Azhar University, Egypt[a].

Department of Obstetrics and Gynecology, Faculty of Medicine, Helwan University, Egypt ${ }^{[\mathbf{b}]}$.

Corresponding author: Mohamed Elsayed Thapet

Email: drthapet@gmail.com

Received at: February 1, 2020; Revised at: April 16, 2020; Accepted at: April 16, 2020; Available online at: April 17, 2020

DOI: 10.21608/ijma.2020.23354.1093

\section{ABSTRACT}

Background: Obesity is a challenging health problem in gynecologic surgery. Laparoscopic has the potential advantages than abdominal hysterectomy of being quicker, efficient with low estimated blood loss.

Aim of the work: To compare the safety and effectiveness of laparoscopic and abdominal hysterectomy for benign conditions in obese patients.

Patients and methods: Sixty patients were submitted to history taking, clinical examination, Lab investigations, abdominal ultrasound and biopsy for suspicious pathology. Patients divided into two equal groups. The first for total laparoscopic hysterectomy and the second for trans-abdominal hysterectomy. Patients were followed-up for six months after surgery. Data collected include operative time, amount of blood loss, complications and duration of hospital stay.

Results: BMI was significantly higher among open when compared to laparoscopic group [43.69 \pm 3.86 vs $34.5 \pm 4.02$ respectively], and low parity and low cesarean deliveries were significantly increased in laparoscopic group. The highest indication of hysterectomy in laparoscopic group was adenomyosis [43.3\%] followed by fibroid [30.0\%], while in open group, the most common indication was fibroid [53.3\%] followed by adenomyosis [26.7\%]. Operative time showed significant decrease in laparoscopic when compared to open hysterectomy groups $[56.23 \pm 21.5 \mathrm{vs}$ $78.87 \pm 8.22$ minutes respectively] and blood loss was significantly decreased among laparoscopic group. Finally, the length of hospital stay was significantly decreased in laparoscopic when compared to open groups [the median was 10 versus 24 hours respectively].

Conclusion: Laparoscopic hysterectomy is superior to abdominal hysterectomy in obese females with benign conditions in terms of safety and efficacy.

Keywords: Laparoscopy; Abdominal; Benign; Hysterectomy; Obesity.

This is an open access article under the Creative Commons license [CC BY] [https://creativecommons.org/licenses/by/2.0/]

Please cite this article as: Thapet ME, Midan MF, Rady MS, Abdou HA. Laparoscopic versus Abdominal Hysterectomy for Obese Women with Benign Diseases. IJMA 2020; 2[2]: 365-372.

* Main subject and any subcategories have been classified according to researchers' main field of study. 


\section{INTRODUCTION}

Hysterectomy [surgical removal of the uterus] was first successfully performed in the 1800s through abdominal or vaginal incisions. Innovations in technology led to the practice of the first hysterectomy by laparoscope in 1989. As of 2009, surveillance data from United States revealed that, $56 \%$ of hysterectomies were abdominal, $20 \%$ laparoscopic, $19 \%$ vaginal and $5 \%$ robotic, when carried out for benign disease[1]. In 1984, Kurt Semm used laparoscopic assistance for complicated vaginal hysterectomy, which followed by rapid advancement in laparo-scopic surgeries. The total laparoscopic hyster-ectomy seems to be advantageous [e.g., had shorter operative time, more efficient, with lower blood loss] when compared to abdominal or vaginal hyster-ectomies and is also more attainable in obese and nulliparous females ${ }^{[2]}$. In addition, laparoscopic hysterectomy [LH] had less perioperative comorbidities, shorter hospital stay duration and faster return to normal daily activities in both obese and non-obese females. However, different studies revealed increased rate of abdominal hysterectomy $[\mathrm{AH}]$ with increased body mass index $[\mathrm{BMI}]^{[3]}$.

Obesity has been considered a pandemic and health challenge, with no difference between low and high-income countries. Globally, the proportion of females with BMI of 25 or more has increased from $30 \%$ to $38 \%$ in 1980 and 2013 respectively. Obesity increased the risk of cardiovascular and endocrinological diseases. In addition, various gynecological comorbidities are related to obesity and overweight, and some of this need hysterectomy [e.g., endometrial cancer, benign indications such as bleeding disorders, fibroids, genital prolapse and endometrial hyperplasia] $]^{[4,5] \text {. }}$

\section{AIM OF THE WORK}

The aim of this trial was to compare the safety, effectiveness and complications of laparoscopic hysterectomy and abdominal hysterectomy for benign conditions in obese patients.

\section{PATIENTS AND METHODS}

This study was a cross-sectional, a prospective study in which 60 patients were selected from those whom attend the Outpatient Gynecological Clinic, at Al-Azhar University Hospital [New Damietta] with indication for hysterectomy and fulfilled the study inclusion criteria. Patient who fulfilled the following criteria were included in the study: 1] Their age above 40 years and below 40 years for highly indicated hysterectomy, 2] BMI: $\geq 30.0 \mathrm{~kg} / \mathrm{m}^{2} ; 3$ ] Size of uterus < 14 week of pregnancy size; and 4] Indications for hysterectomy diagnosed with uterine benign diseases as uterine fibroids, adenomyosis, adnexal masses, .... etc. On the other hand, patients with one or more of the following criteria was excluded from the study: 1] A bulky uterus $>14$ week size, 2] Contraindications for general anesthesia, 3] Systemic infections, 4] Pelvic inflammatory disease, 5] Metastatic metastases, 6] Contraindications to laparoscopy as intraperitoneal mesh and cirrhosis and portal hypertension.

Ethical considerations: The study protocol was approved by the local Ethics and Scientific Research Committee of Damietta Faculty of Medicine, Al-Azhar University [Damietta]. Verbal consents were taken from participants before enrollment in the study. The aim of study was explained to participants and they were reassured about the confidentially and their right of withdrawal of the study at any time. In addition, a sound confirmation about data usage was expressed.

All the patients matched the inclusion criteria were subjected to full history, clinical examination and lab instigations. First, inquiry of detailed history [general, menstrual, obstetric, previous gynecological operation, history of drug intake and associated manifestations] was done. Second, general abdominal and vaginal examinations had been carried out in a systematic pattern. Third, weight and height were measured and body mass index was calculated as weight [kg] divided by squared height [meter]; lab tests included measurement of hemoglobin, blood glucose level. Fourth, ultrasound had been carried out to detect uterine pathology, and biopsy was obtained from suspicion pathology.

The 60 patients had been randomly [closedenvelope method of randomization] categorized into two groups [each contained 30 patients]: First group for total laparoscopic hysterectomy [TLH] and Second group for trans-abdominal hysterectomy [TAH]. Patients with symptomatic benign uterine pathology but with good uterine mobility and uterine 
size less $<14$ weeks were included in the study.

Follow-up: The overall duration of follow up extended for up to six months after hysterectomy. The collected data included operative time, estimated amount of blood loss, duration of hospital stay, early and late postoperative complications. The following definition were used: Operative time was defined as the time of the beginning to the closure of skin incision. Estimated amount of blood loss in total laparoscopic procedure had been defined as the arithmetic difference between fluid used for irrigation and the total volume of liquid in the suction device at the end of the surgery, while blood loss in abdominal hysterectomy were estimated by calculating the blood volume in the suction device, weighing soaked swabs and calibrated mops used during surgery. The duration of hospital stay had been defined as the number of days patient stayed in hospital after surgery after exclusion of the day of surgery. Early post-operative complications included those within the first postoperative week [for example, intestinal and ureteric injuries], while late post-operative complications confined to those developed after the first postoperative week [for example, hernia at trocar site]. The surgical technique of laparoscopic hysterectomy was done as described by Kondo et al.[6].

Analysis of data was carried out by statistical package for social science [SPSS] [Version 15.0; Chicago, Illinois, USA]. Quantitative variables described by their mean, standard deviation and their range. Student [t] tests or Mann-Whitney [U] test were used for comparison between numerical parametric and non-parametric data respectively. The Chi square test $\left[X^{2}\right]$ was used to compare qualitative variables between groups, which presented by their frequency and percentages. Pvalues $\leq 0.05$ had been considered significant.

\section{RESULTS}

In the present study, there was no significant difference between laparoscopic and open hysterectomy groups regarding age distribution [49.93 \pm 8.52 vs $48.87 \pm 5.52$ respectively]. In addition, $60 \%$ and $56.7 \%$ of patients were $\leq 50$ years in open and laparoscopic groups respectively. The BMI was significantly higher among the open when compared to laparoscopic group $[43.69 \pm 3.86$ vs $34.5 \pm 4.02$ respectively]. However, the degree of obesity showed no significant difference between both groups. In the laparoscopic group, $60 \%$ were of grade-I obesity, $23.3 \%$ were grade-II and only $16.7 \%$ were of morbid obesity; while in open group, $36.7 \%$ were of morbid obesity, $33.3 \%$ grade-II obesity and $30.0 \%$ were grade-l obesity. The previous birth less than 3 was significantly increased in laparoscopic when compared to open group [100.0\% vs $36.7 \%$ respectively]. In addition, previous cesarean section [CS] less than 3 was significantly higher among laparoscopic when compared to open group [100.0\% vs $80.0 \%$ respectively]. However, no significant difference was observed between groups regard past history of surgery other than CS [Table 1]. In addition, there was no significant difference between laparoscopic and open hysterectomy groups regarding medical disorders [it was positive in $60.0 \%$ and $70.0 \%$ in laparoscopic and open groups respectively]. However, there was significant increase of past history of viral hepatitis in open when compared to laparoscopic groups $[16.7 \%$ vs $0.0 \%$ respectively]. The highest indication of hysterectomy in laparoscopic group was adenomyosis [43.3\%] followed by fibroid [30.0\%], while in open group, the most common indication was fibroid [53.3\%] followed by adenomyosis [26.7\%] with no significant difference between both groups. Clinically, bleeding was significantly increased and pain was significantly decreased among laparoscopic when compared to open groups [86.7\% and $20.0 \%$ vs $46.7 \%$ and $43.3 \%$ respectively] [Table 2]. Operative time ranged between 22 and 124 minutes with significant decrease in laparoscopic when compared to open groups [ $56.23 \pm 21.5$ vs $78.87 \pm 8.22$ minutes respectively]. In addition, the blood loss was significantly decreased in laparoscopic when compared to open groups [the median was 1000 and $210 \mathrm{ml}$ respectively]. Finally, the length of hospital stay was significantly decreased in laparoscopic when compared to open groups [the median was 10 versus 24 hours respectively] [Table 3]. Intraoperatively, early and late postoperative complications were higher among open when compared to laparoscopic groups $[6.7 \%, 13.3 \%$ and $16.7 \%$ versus $0.0 \%, 3.3 \%$ and $0.0 \%$ successively]. However, the difference was statistically nonsignificant [Table 4]. 
Thapet ME, et al.

Table [1]: Patient demographics, and past history among studied groups

\begin{tabular}{|c|c|c|c|c|c|c|}
\hline & Laparoscopic hysterectomy & Open hysterectomy & test & $\mathrm{P}$ \\
\hline \multicolumn{3}{|c|}{ Age/years } & $49.93 \pm 8.52$ & $48.87 \pm 5.52$ & 0.58 & 0.57 \\
\hline \multirow{2}{*}{\multicolumn{2}{|c|}{$\begin{array}{l}\text { Age } \\
\text { group }\end{array}$}} & $\leq 50$ & $17[56.7 \%]$ & $18[60.0 \%]$ & \multirow{2}{*}{0.07} & \multirow{2}{*}{0.79} \\
\hline & & $>50$ & $13[43.3 \%]$ & $12[40.0 \%]$ & & \\
\hline \multicolumn{3}{|c|}{ BMI $\left[\mathrm{kg} / \mathrm{m}^{2}\right]$} & $34.5 \pm 4.02$ & $43.69 \pm 3.86$ & 2.36 & $0.02^{*}$ \\
\hline \multirow{3}{*}{\multicolumn{2}{|c|}{$\begin{array}{l}\text { Obesity } \\
\text { Class }\end{array}$}} & I & $18[60.0 \%]$ & $9[30.0 \%]$ & \multirow[t]{3}{*}{5.78} & \multirow[t]{3}{*}{0.06} \\
\hline & & II & $7[23.3 \%]$ & $10[33.3 \%]$ & & \\
\hline & & III & $5[16.7 \%]$ & $11[36.7 \%]$ & & \\
\hline \multirow{7}{*}{$\begin{array}{l}\text { Past } \\
\text { History }\end{array}$} & \multirow{2}{*}{$\begin{array}{l}\text { Previous } \\
\text { birth }\end{array}$} & $<3$ & $30[100.0 \%]$ & $11[36.7 \%]$ & \multirow[t]{2}{*}{27.81} & \multirow[t]{2}{*}{$<0.001^{*}$} \\
\hline & & $\geq 3$ & $0[0.0 \%]$ & $19[63.3 \%]$ & & \\
\hline & \multirow{2}{*}{$\begin{array}{l}\text { Previous } \\
\text { CS }\end{array}$} & $<3$ & $30[100.0 \%]$ & $24[80.0 \%]$ & \multirow[t]{2}{*}{6.67} & \multirow[t]{2}{*}{$0.01^{*}$} \\
\hline & & $\geq$ & $0[0.0 \%]$ & $6[20.0 \%]$ & & \\
\hline & \multirow{3}{*}{$\begin{array}{l}\text { Surgery other } \\
\text { than CS }\end{array}$} & Negative & $21[70.0 \%]$ & $15[50.0 \%]$ & \multirow[t]{3}{*}{4.13} & \multirow[t]{3}{*}{0.12} \\
\hline & & Once & $8[26.7 \%]$ & $15[50.0 \%]$ & & \\
\hline & & Twice & $1[3.3 \%]$ & $0[0.0 \%]$ & & \\
\hline
\end{tabular}

BMI: Body mass index, CS: cesarean section; *: significant

Table [2]: Medical disorders, indications and clinical signs of hysterectomy among studied groups

\begin{tabular}{|l|l|c|c|c|c|}
\hline \multicolumn{2}{|c|}{} & Laparoscopic hysterectomy & Open hysterectomy & test & P \\
\hline \multirow{2}{*}{ Medical disorders } & Negative & $12[40.0 \%]$ & $9[30.0 \%]$ & \multirow{2}{*}{0.66} & \multirow{2}{*}{0.42} \\
\cline { 2 - 5 } & Positive & $18[60.0 \%]$ & $21[70.0 \%]$ & & \\
\hline DM & & $6[20.0 \%]$ & $6[20.0 \%]$ & 0.01 & 1.0 \\
\hline Hypertension & $14[46.7 \%]$ & $7[23.3 \%]$ & 3.59 & 0.06 \\
\hline IHD & $3[10.0 \%]$ & $3[10.0 \%]$ & 0.01 & 1.0 \\
\hline DVT & $1[3.3 \%]$ & $0[0.0 \%]$ & 1.0 & 0.31 \\
\hline AF & $1[3.3 \%]$ & $1[3.3 \%]$ & 0.01 & 1.0 \\
\hline Asthma & $1[3.3 \%]$ & $1[3.3 \%]$ & 0.01 & 1.0 \\
\hline Viral hepatitis & & $0[0.0 \%]$ & $5[16.7 \%]$ & 5.46 & $0.02^{*}$ \\
\hline \multirow{2}{*}{ Indications of } \\
hysterectomy & Failed hormonal therapy & $3[10.0 \%]$ & $5[16.7 \%]$ & & \\
& Endometrial hyperplasia & $1[3.3 \%]$ & $0[0.0 \%]$ & & \multirow{3}{*}{0.16} \\
\cline { 2 - 5 } & Ovarian mass & $4[13.3 \%]$ & $1[3.3 \%]$ & \\
\cline { 2 - 5 } & Adenomyosis & $13[43.3 \%]$ & $8[26.7 \%]$ & & \\
\cline { 2 - 5 } & Fibroid & $9[30.0 \%]$ & $16[53.3 \%]$ & & \\
\hline \multirow{2}{*}{ Clinical signs } & Bleeding & $26[86.7 \%]$ & $14[46.7 \%]$ & 10.8 & $0.001^{*}$ \\
\cline { 2 - 5 } & Pain & $6[20.0 \%]$ & $13[43.3 \%]$ & 3.77 & $0.05^{*}$ \\
\hline
\end{tabular}

DM: Diabetes mellitus; IHD: Ischemic heart disease; DVT: Deep venous thrombosis; AF; Atrial fibrillation; *: significant

Table [3]: Operative details among studied groups

\begin{tabular}{|c|c|c|c|c|}
\hline \multicolumn{2}{|c|}{} & $\begin{array}{c}\text { Laparoscopic hysterectomy } \\
\mathrm{N}=30\end{array}$ & $\begin{array}{c}\text { Open hysterectomy } \\
\mathrm{N}=30\end{array}$ & test of significance \\
\hline \multirow{2}{*}{$\begin{array}{c}\text { Operative Time } \\
{[\text { minutes] }}\end{array}$} & {$[$ mean \pm SD] } & $56.23 \pm 21.5$ & $78.87 \pm 8.22$ & $\mathrm{t}=5.38$ \\
\cline { 2 - 5 } & {$[$ Min-max] } & {$[22.0-124.0]$} & {$[22.0-124]$} & $P<0.001^{*}$ \\
\hline $\begin{array}{c}\text { Blood loss } \\
{[\mathrm{ml}]}\end{array}$ & median & 100.0 & 210 & $\mathrm{Z}=5.19$ \\
\cline { 2 - 5 } & {$[$ Min-max] } & {$[50.0-600.0]$} & {$[150-300]$} & $P<0.001^{*}$ \\
\hline $\begin{array}{c}\text { Length of hospital stay } \\
{[\text { hours] }}\end{array}$ & Median & 10.0 & 24.0 & $\mathrm{z}=6.07$ \\
\cline { 2 - 5 } & {$[$ Min-max] } & {$[10.0-24.0]$} & {$[24-72]$} & $p<0.001^{*}$ \\
\hline
\end{tabular}

*: significant

Table [4]: Complications among studied groups

\begin{tabular}{|l|c|c|c|c|}
\hline & Laparoscopic hysterectomy & Open hysterectomy & Test & $p$ \\
\hline Intraoperative complications & $0[0.0 \%]$ & $2[6.7 \%]$ & 2.06 & 0.49 \\
\hline Early postoperative complications & $1[3.3 \%]$ & $4[13.3 \%]$ & 1.96 & 0.35 \\
\hline Late postoperative complications & $0[0.0 \%]$ & $5[16.7 \%]$ & 1.02 & 0.31 \\
\hline
\end{tabular}




\section{DISCUSSION}

Laparoscopic hysterectomy [LH] had clear advantages over abdominal hysterectomy [AH], as $\mathrm{LH}$ was proven to be feasible and harmless in obese patients and $\mathrm{LH}$ is considered the best practice ${ }^{[7]}$. $\mathrm{LH}$ limits the poor healing of wounds and reduces infections particularly in diabetic patients, and helps earlier recovery with shorter hospital stay as compared to $\mathrm{AH}$ than open procedures ${ }^{[8]}$. Therefore, we carried this study, in which 60 patients with indication for hysterectomy; to compare the safety and effectiveness of laparoscopic hysterectomy and abdominal hysterectomy for benign conditions in obese patients.

The mean age of patient in the present work is comparable to previous study carried out by EI Shakhs et al.[9]. They reported mean age of $54.80 \pm 8.96$ years for LH group versus $51.66 \pm 9.17$ years for open hysterectomy group. They also found no significant association between age and safety, effectiveness or complications of laparoscopic or open hysterectomy for benign conditions in obese patients. In addition, Ali et al.[10] reported no significant difference between the abdominal and laparoscopic groups as regard patients age. However, potentially older females were somewhat increased in laparoscopic group. This coincides with the results of a study of 283 patients concluded that, older females should be assigned for laparoscopic hysterectomy, being cost effective in older age patients [11]. On the other side, Wiser et al.[12] reported that, the proportion of younger women in the LH group was higher compared to the abdominal hysterectomy group [11\% vs. $8 \%$, respectively]. Otherwise, a multi-centre cohort study, recorded significant increase of older females in laparoscopic group [13].

BMI significantly increased in open when compared to laparoscopic group. This comparable to results of Sokol et al.[14] who reported that, a BMI $>30 \mathrm{~kg} / \mathrm{m}^{2}$ increased the risk of abdominal hysterectomy by more than 2-fold. Bhandari et al.[15] reported that, laparoscopic hysterectomy was less convenient in obese patients with $\mathrm{BM}>30 \mathrm{~kg} / \mathrm{m}^{2}$. They explained this by the fact that laparoscopy in obese patients can be technically challenging for the gynecologist but is more rewarding for the patient.
The main technical difficulties because of the increased BMI is the occurrence of pneumoperitoneum. Also, the increased skin thickness, counter traction with absence of skin fold formation in females with higher BMl; vertically directed Veress needle entry yields acceptable results. In thin patients, the Veress may cautiously be directed more towards the pubic symphysis for fear of injury for the major vital structures below umbilicus. In patients with higher BMI, a longer Veress may contribute to low failure of insufflation. In addition, in obese patients, the sustainability of pneumoperitoneum is technically more difficult due to concurrent cardiorespiratory compromise. The inspiratory pressures in obese patients is higher, particularly in Trendelenburg position because of the anterior abdominal wall weight, and reduction of ventilator compliance during surgery by bowel, and omentum.

Comparable results were reported in a recent study, that was carried to assess the interaction between the route of hysterectomy for benign uterine conditions and postoperative co-morbidity among patients categorized by their BMl and to test for a dose-dependent relationship between obesity grade and postoperative complications, where they reported a statistically significant association between hysterectomy route and $\mathrm{BMI}>30^{[16]}$. On the other side, this is different from El Shakhs et al.[9] who reported non-significant difference between laparoscopic and abdominal groups regarding BMI. In addition, Ali et al. [10] reported different results from ours, showing no significant difference between groups regarding BMI.

As regards the previous gynecological operative history, the parity and previous CS were significantly associated to the route of hysterectomy. This comes in line with results from a previous study, that was carried to evaluate the efficacy and safety of $\mathrm{LH}$ in patients with previous CSs and they reported that $\mathrm{LH}$ is not a risk factor for major postoperative complications or injuries of the lower urinary system and TLH may be carried out safely with no long term morbidity for managed intraoperative injuries of lower urinary tract[17].

On the other side, other studies revealed that patients with a previous CS had a higher risk for 
development of post-hysterectomies morbidities over the long-term. Moreover, compared with patients without previous CS, they are more frequently need reoperation after hysterectomy, since they have higher rates of peri and postoperative comorbidities ${ }^{[18,19]}$. However, Ali et al. ${ }^{[10]}$ reported no significant difference between the abdominal and laparoscopic hysterectomies regarding parity, past history of CS and other pelvic surgeries. Also, a multi-center cohort retrospectively compared 4,895 hysterectomies [3,539 LH vs.1,356 $\mathrm{AH}$ ] through duration between 2007 and 2013, with evaluation of the short- and long-term outcomes in benign gynecological disease, yielded different results. They revealed that, previous cesarean delivery or abdominal surgeries did not differ significantly between groups ${ }^{[20]}$.

Medical disorders among studied cases [Diabetes, hypertension, ischemic heart diseases, deep vein thrombosis, atrial fibrillation and asthma], seems not to affect the route of hysterectomy. However, the presence of hepatitis favors $\mathrm{AH}$. The presence of viral hepatitis hinders LH. He et al.[20] reported similar results to ours, where they reported that presence of medical comorbidities did not differ significantly between either groups. However, these results differ than previous studies, where it was reported that patients with DVT should better undergo laparoscopic hysterectomy [12], as immovability is a well-known risk factor for DVT[21], and short duration of hospital stay was described as useful in prevention of PE. The LH group had a significantly shorter hospital stay which may explain the lower rate of DVT as described by Cotter et al.[22].

The highest percentage of patients undergoing AH had fibroid. However, adenomyosis was the most common in LH group. In agreement with our results, Ali et al.[10], reported that fibroid represented the most common indication for $\mathrm{AH}$ [40\%], vaginal hysterectomy [36\%] and Laparoscopic hysterectomy [48\%]. Also, Kulvanitchaiyanunt[23] reported that fibroid uterus was the commonest indication of $\mathrm{LH}$.

The operative time was highly significantly shorter among laparoscopic group. This comes in line Sesti et al.[24] found that $\mathrm{LH}$ took shorter time [125 6 min.] vs. [133 $\pm 7 \mathrm{~min}$.] for $\mathrm{AH}$. In contrast to our results, Ali et al.[10] reported that the operative time was significantly longer in the $\mathrm{LH}$ group compared to the $\mathrm{AH}$ and $\mathrm{VH}[110.67 \pm 35.6$ min vs. $69.3 \pm 27.9 \mathrm{~min}$ and $58.9 \pm 15.2 \mathrm{~min}$ ], they attributed this to the fact that this technique needs more time to gain acceptance and more skill for surgical training. van Evert et al. [13] reported different results, where they reported that the operating time was not significantly different between both groups.

The amount of blood loss was highly significant among the open hysterectomy group. This is in line with different previous trials where the estimated blood loss was significantly lower in LH compared to $\mathrm{AH}^{[10,24-26]}$ Lowell and Kessler ${ }^{[27]}$ reported different results, where they reported that $\mathrm{LH}$ had more estimated blood loss than $\mathrm{AH}$ this was attributed to the non-selection of specific criteria for cases for $\mathrm{LH}$, they did not exclude large myomatus uteri reaching $500 \mathrm{gm}$. van Evert et al.[13] also reported different results, where they reported that the blood loss was not significantly different between both groups.

The length of hospital stay was very significant shorter among laparoscopic group. This agree with Ali et al. ${ }^{[10]}$, who recorded that the length of hospital stay was significantly shorter in patients with $\mathrm{LH}$. In addition, Zhang et al..[28] and Sesti et al. ${ }^{[24]}$ found that postoperative hospital stay after LH was significantly shorter in comparison to $\mathrm{AH}$ group. The shorter hospital stay with LH might be attributed to early ambulation associated with $\mathrm{LH}$ due to the small incision and the less postoperative pain and therefore short hospital stay which is considered one of the valuable advantages of laparoscopic approach over $\mathrm{AH}^{[10]}$.

Intraoperative complications were about $6.7 \%$ in open hysterectomy, early and late postoperative complications were higher in $\mathrm{AH}$ group [about 13.3\% and $16.7 \%$ respectively]. However, there was no significant difference between both groups in complications in general. This comes in line with the results reported by Ali et al..[10], where, there were no significant differences between abdominal and laparoscopic groups as regard the incidence of major operative complications.

We can conclude that $\mathrm{LH}$ is more preferable than $\mathrm{AH}$, being a minimally invasive gynecological procedure, more preferred for older women, with loss estimated blood loss and associated with shorter operative time and hospital stay. In addition, it 
permits a faster recovery time and minimal complications. However, it needs surgeon's experience and expertise.

We recognize some limitations in our study; first of all, the cross-sectional nature of the study design may have several drawbacks, where it cannot be used to analyze behavior over a period of time, does not help to determine the cause-effect relationship, the timing of the study is not guaranteed to be representative, and it may be subjected to some challenges where this cross sectional study may not be really representative of the whole population. Also, the small sample size hinders the generalization of the results. Third point is the presence of confounding variable not unified in our study, which make the results subjected to bias, with consequent underestimation of possible adverse events.

There are a number of strengths in our study, a clear definition of TLH was applied, and the suspicion for any vaginal component to the laparoscopic hysterectomy lead to exclusion from analysis. Also, the inclusion/exclusion criteria for our study were judiciously consistent [benign indications only, no metastatic metastases, only large uterus < 14 weeks, no significant pelvic inflammatory disease, no indication for adnexal surgery, no contraindications for general anesthesia, no systemic infections, and no contraindications to laparoscopy as intraperitoneal mesh and cirrhosis or portal hypertension]. Further longitudinal studies in multicenter are needed to elucidate the clinical implications of our results. Also, future studies will provide both clinicians and researchers with new understandings for $\mathrm{LH}$ in obese patients, particularly those with morbid obesity. Finally, we can confirm the fact that laparoscopic skills can be taught and advanced, we believe training efforts and sophistication of technology will allow more and more laparoscopists to deal successfully with any difficult case.

\section{REFERENCES}

1. Cohen SL, Vitonis AF, Einarsson Jl. Updated hysterectomy surveillance and factors associated with minimally invasive hysterectomy. JSLS 2014; 18[3]. [DOI:10.4293/JSLS.2014.00096].

2. Scribner DR, Walker JL, Johnson GA, Mcmeekin SD, Gold MA, Mannel RS. Laparoscopic pelvic and Para aortic lymph node dissection: analysis of the first 100 cases. Gynecol Oncol. 2001; 82:498-503. [DOI:10.1006/ gyno.2001.6314].

3. Aarts JW ${ }^{1}$, Nieboer TE, Johnson N, Tavender E, Garry R, Mol BW, Kluivers KB. Surgical approach to hysterectomy for benign gynecological disease. Cochrane Database Syst Rev. 2015; [8]:CD003677 [DOI:10.1002/14651858. CD003677.pub5].

4. Morgan-Ortiz F1, Soto-Pineda JM, López-Zepeda MA, Peraza-Garay Fde J. Effect of body mass index on clinical outcomes of patients undergoing total laparoscopic hysterectomy. Int J Gynaecol Obstet. 2013; 120[1]:61-4. [DOI:10.1016/j.ijgo.2012.08.012]

5. Hardy R, Wadsworth M, Kuh D. The influence of childhood weight and socioeconomic status on change in adult body mass index in a British national birth cohort. Int $\mathrm{J}$ Obes Relat Metab Disord. 2000; [24]: 725-34. [DOI:10.1038/ sj.ijo.0801238].

6. Kondo W, Zomer MT, Charles L, Bourdel N, Mage G, Canis M. Total Laparoscopic Hysterectomy: Surgical Technique and Results. In: Advanced Gynecologic Endoscopy. Atef Darwish [ed], InTechOpen 2011, pp 263292. [DOI: 10.5772/20224].

7. Blikkendaal MD, Schepers EM, van Zwet EW, Twijnstra AR, Jansen FW. Hysterectomy in very obese and morbidly obese patients: a systematic review with cumulative analysis of comparative studies. Arch Gynecol Obstet. 2015; 292: 723-38. [DOI: 10.1007/s00404-0153680-7].

8. Matthews KJ, Brock E, Cohen SA, Chelmow D. Hysterectomy in obese patients: special considerations. Clin Obstet Gynecol. 2014; 57 [1]:106-14. [DOI:10.1097/ GRF.0000000000000005].

9. El Shakhs SA, Mohamed MA, Shahin MA, Eid AM: Laparoscopic versus open hysterectomies in obese patients. Int Surg J. 2018; 5[12]:3893-3897. [10.18203/ 2349-2902.isj20185014].

10. Ali SA, Farahat MM, EIShafei MAM. Surgical Approach to Hysterectomy for Benign Gynecological Diseases. Egy J Hospital Med 2019; 77 [3]: 5279-5286. [DOI: 10.12816/ ejhm.2019.55490].

11. Bijen $C B$, de Bock $G H$, Vermeulen KM, Arts HJ, ter Brugge HG, van der Sijde $R$, et al. Laparoscopic hysterectomy is preferred over laparotomy in early endometrial cancer patients, however not cost effective in the very obese. Eur J Cancer. 2011; 47[14]:2158-65. [DOI: 10.1016/ j.ejca.2011.04.035].

12. Wiser A, Holcroft CA, Tulandi $T$, Abenhaim HA. Abdominal versus laparoscopic hysterectomies for benign diseases: evaluation of morbidity and mortality among 465,798 cases. Gynecol Surg. 2013; 10; 117-122. [DOI: 10.1007/s10397-013-0781-9].

13. van Evert JS, Smeenk JM, Dijkhuizen FP, de Kruif JH, Kluivers KB. Laparoscopic subtotal hysterectomy versus laparoscopic total hysterectomy: a decade of experience. Gynecol Surg. 2010 Feb; 7[1]: 9-12. [DOI: 10.1007/ s10397-009-0529-8].

14. Sokol Al, Chuang K, Milad MP. Risk factors for conversion 
to laparotomy during gynecologic laparoscopy. J Am Assoc Gynecol Laparosc. 2003; 10[4]:469-73. [DOI: 10.1016/s1074-3804 [05]60146-6].

15. Bhandari S, Agrawal P, Singh A. Body Mass Index and Its Role in Total Laparoscopic Hysterectomy. Int Sch Res Notices. 2014 Oct 28; 2014:787604. [DOI:10.1155/2014/ 787604].

16. Tyan $P$, Amdur R, Berrigan $M$, Robinson $H$, Sparks $A$, Gu A, et al. Differences in Postoperative Morbidity Among Obese Patients Undergoing Abdominal versus Laparoscopic Hysterectomy for Benign Indications. J Minim Invasive Gynecol. 2019 Apr 6. pii: S1553-4650 [19]301499. [DOI: 10.1016/ j.jmig.2019.04.001].

17. Koroglu N, Cetin BA, Turan G, Yıldırım GY, Akca A, Gedikbasi A. Characteristics of total laparoscopic hysterectomy among women with or without previous cesarean section: retrospective analysis. Sao Paulo Med J. 2018; 136[5]:385-389. [DOI:10.1590/1516-3180.2018. 0197030718].

18. Wong JMK, Bortoletto P, Tolentino J, Jung MJ, Milad MP. Urinary Tract Injury in Gynecologic Laparoscopy for Benign Indication: A Systematic Review. Obstet Gynecol. 2018; 131[1]:100-8. [DOI:10.1097/AOG. 000000000000 2414].

19. Sinha R, Sundaram M, Lakhotia S, Hedge A, Kadam P. Total laparoscopic hysterectomy in women with previous cesarean sections. J Minim Invasive Gynecol. 2010; 17[4]:513-7. [DOI: 10.1016/ j.jmig. 2010.03.018].

20. He H, Yang Z, Zeng D, Fan J, Hu X, Ye Y, et al. Comparison of the short-term and long-term outcomes of laparoscopic hysterectomies and of abdominal hysterectomies: a case study of 4,895 patients in the Guangxi Zhuang Autonomous Region. Chin J Cancer Res. 2016; 28 [2]: 187-96. [DOI: 10.21147/j.issn.1000-9604.2016. 02. 06].

21. Brasileiro $A L$, Miranda $F$ Jr, Ettinger JE, Castro AA, Pitta GB, de Moura LK, et al. Incidence of lower limbs deep vein thrombosis after open and laparoscopic gastric bypass: a prospective study. Obes Surg. 2008; 18:52-57. [DOI: 10.1007/s11695-007-9268-y].
22. Cotter SA, Cantrell W, Fisher B, Shopnick R. Efficacy of venous thromboembolism prophylaxis in morbidly obese patients undergoing gastric bypass surgery. Obes Surg. 2005; 15:1316-1320. [DOI:10.1381/ 096089205774512 $690]$.

23. Kulvanitchaiyanunt $A$. A retrospective and comparative study between laparoscopically assisted vaginal hysterectomy [LAVH] and total abdominal hysterectomy [TAH] J Med Assoc Thai. 2004; 87 [7]:745-9. [PMID: 15521227].

24. Sesti F, Ruggeri V, Pietropolli A, Piccione E. Laparoscopically assisted vaginal hysterectomy versus vaginal hysterectomy for enlarged uterus. JSLS 2008; 12[3]: 246. [PMID: 18765046].

25. Hwang JH, Lim MC, Joung JY, Seo SS, Kang S, Seo HK, Chung J, Park SY. Urologic complications of laparoscopic radical hysterectomy and lymphadenectomy. Int Urogynecol J 2012; 23: 1605-1611. [DOI: 10.1007/ s00192- 012-1767-2].

26. Atabekoglu C, Sönmezer M, Güngör M, Aytaç R, Ortaç $\mathbf{F}$, Ünlü C. Tissue trauma in abdominal and laparoscopicassisted vaginal hysterectomy. J Am Assoc Gynecol Laparosc. 2004; 11[4]:467-72. [DOI: 10.1016/s10743804[05]60077-1].

27. Lowell L, Kessler AA. Laparoscopically assisted vaginal hysterectomy. A suitable substitute for abdominal hysterectomy? J Reprod Med. 2000; 45[9]:738-42. [PMID: 11027083]

28. Zhang Y, Lee ET, Cowan LD, North KE, Wild RA, Howard BV. Hysterectomy prevalence and cardiovascular disease risk factors in American Indian women. Maturitas 2005; 52[3-4]: 328-336. [DOI: 10.1016/j.maturitas.2005.05.009]. 